\title{
Modern Education: Immersive Discourse
}

\author{
Larisa Bykasova ${ }^{1}$, Mikhail Kravchenko ${ }^{1}$, Elena Kamenskaya ${ }^{1}$, Margarita \\ Krevsoun ${ }^{1}$, Irina Samoilova ${ }^{1}$
}

${ }^{1}$ Rostov State Economic University, Rostov, Russia

*Email: moeve-25-moeve@yandex.ru

\begin{abstract}
From the essential approach position, the article examines the modern educational organization formation and functioning as a scientific, educational, training, socio-cultural object that meets the needs of a society; the domestic pedagogical education development priorities and directions are determined; the prospects for the formation of the modern pedagogical knowledge are exposed: digitalization, network interaction, remote type of information transfer, subject's generation of all possible alternatives to identify the individual balance of the personality; the dynamics and methodological optics of the modern university research process is analyzed; the ways of the pedagogical education available resources rational use are discussed; the methodological practice and the ways of the new practices subsequent multiplication in the university education system, are reflected; the factors, influencing the quality of the modern subject education are established; the toolkit of specialist's training and education, demanded by the labor market, is investigated; an approach is implemented, identifying a modern student in his development, which helps to determine the pedagogical substance movement nature, to recreate a holistic picture of the available reserves and means necessary for the personality education at a qualitative level.
\end{abstract}

Keywords: Didactic potential, Intelligent Activity of a person, Artificial environment, Education system modernization.

\section{INTRODUCTION}

The modern education is a complex content, characterized with the holographic nature of the conceptual provisions about the pedagogical theory and practice development, with the educational landscape heterogeneity, and with the platform solutions causality.

Education is a living mechanism, liable to the transformational and innovative processes. We should consider the modern education practice from the point of view of its immersiveness in search of the innovative foundations for the education structure harmonization, for the further development of the pedagogical design. Immersiveness is a technology of immersion in the virtual world or various types of real and virtual reality mixing [1].

The concept of "immersive technologies" can be increasingly frequently found in the modern pedagogical science. The immersive technologies (virtual and augmented reality, $360^{\circ}$ video) are also called the augmented reality technologies, as they provide:

- the effect of person's full or partial presence in the alternative space (changing their user-defined experience in various spheres) [2];

- the interaction of the objective reality, where we find ourselves and which we perceive with the senses, and the virtual reality, i.e. the simulated reality using the modern technologies (3D, sound, tactile sensations) [3];

- the synergy of the augmented, mixed and extended reality (i.e. we add the elements of virtual, purposefully modeled reality to our reality (RR)) [4].

The immersive art is aimed at the development of the sensory perception, at expanding the consciousness boundaries through the emotional impact on the viewer, at the facts' accumulation and generalization, at the cognition of the surrounding reality in a figurative form of the laws. It is known that the scientific cognition and 
the cognition with the help of art are based on the same approaches, although there is no complete identity. This is confirmed by the analysis of the works of the domestic leading psychologists, namely M.Yu. Chernyshev, A.M. Zhuravleva (supporters of the non-verbal communication development) [5]; E.V. Ilyenkov (follower of the development of the person's ability to think) [6]; A. Yasnitsky [7], A. R. Luria [8] (supporters of the human mental development); L.S. Vygotsky, A.A. Puzyrei (followers of the higher nervous activity study) [9]. It is also shown in the foreign scientists' works: C. Junge, P. Valkenburg, M. Dekovich, S. Branje (adherents of individuals' emotional communication), etc. [10].

We define the immersive nature of art as the subject area of our research. According to leading psychologists, the future belongs to the development of the immersive discourse in art. Thus, I.A. Yurov believes that the immersive art is able to expand the boundaries of consciousness through the emotional impact on the viewer [11]. V.P. Zinchenko is convinced that the immersive art is aimed at developing the sensory perception [12]. E.G. Simonova rightly decides that due to the immersive nature of art, the education subject accumulates and generalizes the facts about the surrounding reality [13]. A. Yasnitsky comes out with a greater proportion of classes with the use of the immersive discourse which expands the boundaries of cognition in a figurative form, it helps to comprehend the laws of the surrounding reality [7].

We should answer the following questions in the article: what and how people know in art, what and how they realize in immersive discourse, with whom and how they communicate, what are their artistic needs and how they satisfy these necessities.

\section{MATERIALS AND METHODS}

We should define the materials and research methods to reflect on the phenomenon of immersiveness. In our article, the methodological regulations are the method of predicting the modern education functioning; essential and systemic analysis that makes it possible to identify the mission of education in the changed conditions of the 21 st century, i.e. it consists in transferring composite knowledge to the subject; in the expansion of the educational palette and the design of modern pedagogical design, in the institutionalization of the educational process and the integration of educational subjects for their subsequent capitalization; in the individualization and personification of education, forming a harmoniously developed personality with the help of various art practices.

An example of the immersive technology can be a lesson where the teacher tries to "submerge" the students in the discussed pedagogical situation, scene, or quest [14]. The art forms some value judgments, so it reflects the phenomena from almost all spheres of the human life. As the strongest means of teaching and upbringing, the art turns to the assessments in all aspects: philosophical, moral, historical, legal, communicative, etc.

The personality receives its structure from the specific framework of the human activity, therefore it is characterized by five potentials: gnosiological, axiological, creative, communicative, artistic [15]. There is no unambiguous answer to the question of the relationship between cognition in science and art in the modern pedagogical literature. We should consider the formative potential of the education using the example of the impact of art on a person. We choose art under the following reasons:

1) social significance of art [16];

2) transparency of artistic processes [7];

3) semiotic value of the works of art [8];

4) hermeneutic meanings of the works of art[17];

5) capitalization of a person thanks to art activity [8];

6) analytical character in creative work [11];

7) development of artistic design thinking [18];

8) cathartic function of art [8];

9) tactile communication [7];

10) visual attitude of the psyche (in the education process, the understanding of the composition is expanded, the degree of consciousness of the image elements management is increased, the palette of materials textures is enriched, etc.) [19].

We should dwell on the last thesis in more detail. From time immemorial, the artists have appreciated the tactile nature of the used materials when working on a work of art. So, for example, a wax ballerina doll in a tutu (E. Degas 1881), which bodice is made of tulle, the head is decorated with real hair tied in a bun with a satin ribbon, violates the prevailing tradition of applying a certain range of materials. The artist was convinced that this greatly contributes to the formation of the subject's education through the cultural samples' comprehension, that is why the master calls for expanding significantly the range of their use and combination with each other.

\section{RESULTS}

Various mechanisms of the subject's cultural comprehension are used in the education practice through the personality formation prism. We should consider the main mechanisms in more detail.

I. The tactual sense is a process of complex perception of the impact of mechanical, temperature and other external factors by the organism, carried out with the help of receptors located in the skin, muscles, 
tendons, joints, etc. [20]. Touching is a special feeling caused by the touch of the skin to various solids and liquids. In this case, the skin plays the role of a special sense organ. The sense of touch includes feelings of touch, feelings of pressure, aggregating, what is commonly called, the tactile sensations. We can explain the role that the tactual sense plays in art teaching, based on the brain research results, as an integral part of the educational process. Touching is a fundamental vision, the main instrument of human knowledge [8].

Touching (tactile experience and tactile feelings) is evoked in the subject due to the various materials application: threads, feathers, foil, wool, foliage, silk, shells, etc. Thanks to the tactual sense, the student learns the texture of the material, object, sensations, caused by touching it: smooth - rough stone, warm - cold surface of the fabric, soft feather - hard shell, warm - cold object, light - heavy canvas, round - square crayon, etc.

While perceiving a work of art, it is important for a student to understand the differences in the structure of materials in order to comprehend the degree of their influence on the nature of the canvas, collage, author's product. The material is the substantial "body" of art in the artistic activity, which is necessary for an artist in the creative process: granite, sanguine, theatrical props, stage or film set, etc. The material can captivate the student, it can excite their imagination, a creative impulse to modify the original product. It can also delight the artist with their pliability or upset with an unrealized idea.

When comprehending the properties of a material, the education subject undergoes an important process of conceiving the various properties and qualities of materials. We should turn to the classification of materials used in the education process applying the immersive technology. In this regard, we formalize the available data and describe the artistic materials and tools in Table 1 in detail.

When grouping materials and means, we divide them into four groups with a certain degree of convention. The first group is material resources that ensure tactical and strategic success for trainees with tactile contact in the analysis of materials, and later, in the creation and reflection of a work of art. The second group is the logical means, used by the learner in the creative act (especially important for extrability). The third group describes the linguistic means, applied by the learner in the process of semiotic and hermeneutic analysis of a work of art (development of the limbic system). In the classification, the fourth group is the mathematical means, used by the teacher and tactilely perceived by the student in the manufacture and analysis of products, made of clay, plaster, leather, wood, etc.

The table shows that the palette of materials, used in the education subject artistic creation, is diverse that gives preferences to students in comprehending art: it expands their horizons, it forms an aesthetic taste, it enriches vocabulary, it develops erudition.

The tactual sense is important when perceiving works of contemporary art. In today's world of high speeds and the dominance of mass media from various angles (flat, virtual, two-dimensional and three-dimensional images), at first glance, it seems excessive to consider the mission of the material so deeply and fundamentally. However, for a productive life of a subject in the modern world, they need not only the development of the ability to contemplate an artistic product, but also to reflect, that is,

Table 1. Classification of art materials

\begin{tabular}{|c|c|c|}
\hline No. & $\begin{array}{l}\text { Name of } \\
\text { means }\end{array}$ & Characteristics of means \\
\hline 1. & $\begin{array}{l}\text { Material } \\
\text { resources }\end{array}$ & $\begin{array}{l}\text { - knowledge in the field of chemistry (paints, their properties, color change while } \\
\text { mixing, etc.); } \\
\text { - knowledge in the field of physics (resistance of a material, change in its } \\
\text { properties during heating, cooling, friction); } \\
\text { - a palette of materials (use for drawing not only famous materials (watercolor, } \\
\text { sanguine, gouache), but also caramel, ice cream, silver threads, etc.); }\end{array}$ \\
\hline 2. & Logic tools & the logic of a piece of music, a story, a performance, the subject's imagination; \\
\hline 3. & $\begin{array}{l}\text { Language } \\
\text { means of } \\
\text { artistic activity }\end{array}$ & $\begin{array}{l}\text { the language of art is characterized by the specific signs, semiotics, while the sign } \\
\text { is an object of communication between the artist and the recipient; }\end{array}$ \\
\hline 4. & $\begin{array}{l}\text { Mathematical } \\
\text { tools }\end{array}$ & $\begin{array}{l}\text { striving for mathematical accuracy in reflecting reality: the proportions of the } \\
\text { "golden section", the proportions of the human body, the geometric shapes usage } \\
\text { (square, circle, rhombus), ornaments, etc. }\end{array}$ \\
\hline
\end{tabular}

Source: [Compiled by the authors]. 
to think about this product. Therefore, teachers need to teach how to "read" a work of art (understanding, interpretation, hermeneutic, semiotic, iconological analysis, pre-iconographic description, etc.).

Since the times of antiquity, the thesis about teaching of "reading" a work of art is logically connected with the need to develop the tactual sense skills. This philosophical discourse has not lost its significance today, since the use of various materials for the artistic product manufacture is not only the expression of the artistic, aesthetic relations of the subject to the contemporary art, but also a complex of the subject's various activities:

1) transforming activity (for example, weaving products of various shapes from a variety of materials: vine, thread, seaweed, etc.);

2) cognitive activity (for example, combining substances / colour to paint an art piece gives a new resulting effect);

3) assessing activity (the subject can realize the value of their artistic work, its necessity, the applied value of the product, etc.);

4) communicative activity (in the process of creativity, the communication arises not only between the participants, but also some hermeneutic practices between the creator of the artistic canvas and the education subject appear prominently);

5) playing activity (the production of an artistic product takes place in a different atmosphere: emancipation, excitement, competition, which is caused by the creative activity peculiarity, leading to the creation of a new reality, aesthetic attitude, assessment of the world), etc.

All types of activities of the artistic process subject directly begin with the tactual sense (cathartic, suggestive, social, upbringing, heuristic, hedonistic, etc.).

Touching plays an important role in the artistic education of children and adolescents, since the brain in childhood and adolescence is plastic, it constantly forms new neural connections. Therefore, touching (tactile experience and tactile experiences) help the subject to explore the world around them where information is rapidly changing [21]. By training our tactual sense (touching objects, pressing, stroking, stretching, etc.), we train the brain. While the brain works not only more actively, but it also processes much more information: the cognitive functions of the education subject improve, memory is trained, speech improves. To develop mental acuity, it is necessary to apply the cognitive practices in the process of education, namely, touching, as an important mechanism for comprehending culture by the subject.
II. Optics. Vision is one of the most important mechanisms for understanding the world by a person. Vision is the person's ability to perceive light from different objects in the form of special sensations of brightness, color and shape that allows receiving various information about the surrounding reality at a distance [8]. Certainly, such mechanisms as hearing, taste, smell are also important for perception, but we, undoubtedly, comprehend a work of art mainly due to visual sense. Namely thanks to vision a person assimilates more than $90 \%$ of information about the surrounding world. This means that information in the brain is stored and revised not in isolation, but in combination with sensory impressions and sensory integration.

We owe the eye, as an organ of optical perception, the ability to perceive the height and width of things. The optical perception necessarily requires a combination with the tactile representations to obtain the objective information about an object. A certain visual unity is formed through the mental activity, that is, it involves person's active participation in the visual act of the internal activity.

The eye development is one of the main reasons why the art should be represented in the curriculum of an educational institution. The psychological science has revealed the importance of the brain role in the formation of the visual image. The different psychological schools explain this role in various ways. We should present the main conceptual ideas of the leading scientific schools on the role of consciousness in visual perception in Table 2. We will choose three leading scientific schools, in our opinion, whose representatives have made a significant contribution to the development of psychology. The representatives of the first school are interesting for us because they are teachers, psychologists, philosophers who study the connection between optical representations in vision and the intellectual activity of a person in the process of perception. The scientists of the second school are representatives of psychological science whose scientific developments are associated with the study of the cognitive sphere of the subject in the comprehending art process. The third scientific school is represented by the psychologists who analyze visual perception in detail and recognize the leading role of human experience in mastering artistic reality.

The conceptual ideas of the first school of scientists are based on the study of the layers of the education subject consciousness in comprehending art, providing the student with an understanding of the subject's meaning and with the sense, it generates [7]. 
Table 2. Conceptual ideas for the visual image formation

\begin{tabular}{|c|l|l|}
\hline $\begin{array}{c}\text { No. } \\
\text { schoo }\end{array}$ & \multicolumn{1}{|c|}{ Name } & \multicolumn{1}{|c|}{ Conceptual ideas } \\
\hline 1. & $\begin{array}{l}\text { V.P. Zinchenko, Yu. U. Fokht- } \\
\text { Babushkin, B.M. Nemensky, K. } \\
\text { Jaspers, L. Weismantel, E. } \\
\text { Spranger and others }\end{array}$ & $\begin{array}{l}\text { The increasing role of the optical representations in vision is } \\
\text { associated with the intensification in the intelligent subjective } \\
\text { activity of a person in the perception process }\end{array}$ \\
\hline 2. & $\begin{array}{l}\text { L.S. Vygotsky, A.R. Luria, } \\
\text { Wertheimer M., Koffke K., } \\
\text { Koehler W. }\end{array}$ & $\begin{array}{l}\text { S.L. Rubinstein, E.V. Ilyenkov, I. } \\
\text { A. Yurov } \\
\text { with the help of which a person masters the world both in } \\
\text { perceptual and in more complex cognitive processes }\end{array}$ \\
\hline $\begin{array}{l}\text { The recognition of the human experience leading role in } \\
\text { mastering reality. An image on the retina (pattern) is a set of } \\
\text { color spots of a certain configuration, but a person sees objects } \\
\text { in a way, which their consciousness derives the objective reality } \\
\text { from the sensory data. }\end{array}$ \\
\hline
\end{tabular}

Source: [Compiled by the authors].

The opinion of the Gestalt psychology representatives about the visual image formation is the reminiscence of the individual's consciousness development due to the presence of the different generators, which together are considered as a single synchronistic act [8].

The recognition of the human experience leading role in mastering reality is a characteristic of the concept of such scientists as S.L. Rubinstein [20], E.V. Ilyenkov [6], I.A. Yurov [11], who provide a convincing explanation of the consciousness role in visual perception.

Vision differs from other senses in its distance, since information from the outside world comes to the education subject through the waves. The distant nature of vision provides a person with a greater objectivity in its display. Considering objects, a person does not experience the effects of their direct influence, since in visual comprehension the object is separated from perception. Thereby, the perception rises to the level of contemplation, observation, being the source and protoform of all cognition [21].

Vision is not only the registration of what is happening around. Our brain cultivates only part of the information, coming to it from the eyes, and the rest is completed by itself on the basis of the previous experience of contemplating the similar objects. For a possible completion, the brain must understand what it "sees" actually, that is, it not only perceives the sensory signals, but it also interprets them, while the signals receive a semantic load. The artistic activity of the education subject includes the various types of the surrounding reality analysis, among which the visual perception plays the most important role.

\section{DISCOURSE}

The immersive discourse of modern education allows reflecting on the palette of artistic practices, the degree of mastering the artistic norms and patterns by the subject, the level of culture and art.

The analysis of the art education theory and practice makes it possible to assert, with a certain degree of convention, that art, being a reflection of reality, expresses the spiritual life of a modern person. The reason for this phenomenon lies in the uniqueness of art, in its complexity. So, we consider the occupation of trainees with art as a cognitive process, since the subject of

1) uses the semiotic and hermeneutic analysis of the artistic explications and artifacts;

2) develops the limbic system [7];

3) operates with the achievements of anthropology when working on a work of art;

4) focuses on the nuances in the application of various techniques, materials, artistic methods (iconological synthesis, pre-iconographic description, iconographic analysis);

5) shows a mode of creativity: proactive impromptu, fantasy, independence in the use of artistic means; 
6) activates the integration of the creative activity forms (media art, genomic art, algorithms);

7) broadcasts and consolidates someone else's experience in their own artistic activity (making posters, geocultural explications, reflecting ethnocultural symbols in fine art, including ergonometric and engineering characteristics in design).

The foregoing allows us to consider a work of art as a kind of semantic substance, and the intentions of the mental activity of the education subject are one of the main goals of the immersive technology, forming both artistic and non-artistic abilities of a person.

The configuration of the modern education immersive discourse is most clearly manifested in the project activities of students. This is connected with the fact that the project form of work is actively used in the learning process, and it is also included in the field of art: theatrical performance, musical, aesthetic and artistic actions (body-art, ready-made, op-art) [15].

A project of creation an artistic product is a complex type of work that requires sufficient preparation for its implementation, and it has three phases: design, technological phase, reflection. We design an artistic image / system, choosing a project activity in the field of education and engaging in artistic creation. An artistic image is:

1) a general category of the artistic creativity, means and form of mastering life by art;

2) an element or part of a work that has an independent existence and meaning;

3) the way of existence of a work of art (emotional drama, expressiveness, energy, meanings).

In the educational process of the design work, the various methods are used, possessing individual strength and character: classicism, romanticism, realism, sentimentalism, naturalism, modernism, symbolism, acmeism, futurism, impressionism, expressionism, existentialism, postmodernism. Due to this, the expansion of the subject's artistic knowledge is achieved. The experience accumulation happens in the conditions of the free development of the student, in accordance with the development of their consciousness [22].

The project activities immersive nature lies in the fact that a creative environment is composed in the art teaching process: the students independently set forward an artistic idea, they choose a project theme, they also discuss a composition, materials, images, principles of the project implementation, time for the idea realization, a form of the project protection.

In the process of preparing and implementing the project, the teacher acts as a tutor, as an equal member of the team, who perceives all the initiatives of the trainees with respect and attention. The teacher patiently listens to the suggestions and doubts of the students and takes part in search for partners for the project implementation. The instructor attracts the interested persons to finance the large projects (musical, opening day, performance, etc.).

The artistic project defense is the crown of the educational activity, explaining the influence of the produced pedagogical conditions on the successful implementation of the subject's initiative in creativity, revealing the psychological characteristics of the art perception by the education subjects in a combined creative act, exposing the immanent essence of art.

\section{CONCLUSION}

Having studied the indicated problem, we summarize the applied data., We turned to the value foundations of the education practice, the experience of reforming it to understand the immersiveness of modern education from the standpoint of essential and native approaches. All this made it possible to substantiate the need for transformational processes in education through the modernization of programs and infrastructure of scientific research in the field of general and pedagogical education; to consolidate the efforts of the domestic scientific and pedagogical community and foreign partners for the formation of an international network community in the field of education; to initiate the strategic projects for the development of domestic pedagogical education.

We should note that the immersive discourse involves the use of a wide range of different mechanisms in the practice of education for mastering the artistic reality, creating an artistic product, solving a set of tasks that arise when teaching artistic activity, when engaging in creativity: fantasy, communication, the presence of trust / distrust filters in the selection of information, the trainee's personal causality, the development of the limbic system, the subject's search for harmony, the emotional balance in communication with the world. These signs indicate the presence of a holistic type of consciousness in the student. At the same time, the main mechanisms of comprehending an artistic image by a subject are valuable.

The immersiveness of the modern education is clearly expressed in the implementation of the principle of aesthetic mastering the reality of the modern student, that is, it is active interaction and mutual support of the objective and subjective principles where the subjective plays a significant role in psychological and functional terms, since the aesthetic feelings are directly related to the intellectual processes. The regulator of the development of the student's artistic and creative abilities is the experience of using various forms of cognition (perception, experience, mastering the material of art, the development of cognitive thinking). 
Another significant advantage of the immersive discourse in the modern education is the satisfaction of the need for the development of the subject's algocognitive structure, that is, in the management of the further development of education by a new evolutionary mechanism, which is the Internet today, where the student has become the owner of a fundamentally new type of hyper-network that generates phenomena singularities, especially in the comprehension of art. The regularity of the human mind construction of a modern student is a hybrid product where a super-complex hypernetwork form of matter (brain) is intertwined with an invisible symbolic hyper-network (culture), forming a distributed cognitive network

The research in the field of the stated problems allowed us to determine the prospects for the development of the didactic potential of art in the immersive discourse: the formation of the cultural identity of students, the assistance in the implementation of cultural and leisure opportunities and in ensuring the cultural safety of the education subject. This is achieved thanks to the authenticity of the process of viewing and producing an artistic product, using various techniques, materials and forms, as well as by solving the problem of modern education in the immersive discourse: transferring knowledge to the education subject in the field of art in a project form that unites all types of activities of the artistic process subject (cathartic , suggestive, social, upbringing, heuristic, hedonistic), as one of the most progressive in the period of the information and communication technologies development.

The main tendency of the immersive discourse in the modern education is the desire to form consciously the elements of rational thinking of the education subject; it is also the emergence of the communicative discourse (the organization of the dialogical interaction between the teacher and the student, the students among themselves).

The immersive technology has the characteristics of interdisciplinarity and convergence, it uses the recreational resources of art education, working out the scenarios of the socio-cultural development of the individual; it motivates abilities, patterns of behavior and communication, it contributes to the transformation of moral norms that ensures the integration of the individual into the society.

\section{REFERENCES}

[1] J.M. Alzaid, The Effect of Peer Assessment on the Evaluation Process of Students, International Education Studies 10(6) (2017) 159-173.

[2] D. Buckingham, Digital Media Literacies: rethinking media education in the age of the
Internet, Research in Comparative and International Education 2(1) (2007) 43-55.

[3] C.M. Tham, J.M. Werner, Designing and evaluating e-learning in higher education: A review and recommendations, Journal of Leadership \& Organizational Studies 11(2) (2005) 15-25.

[4] A.M. Kondakov, Digital education: a matrix of opportunities, 2018. Retrieved from: http://ito2018.bytic.ru/uploads/materials/2.pdf

[5] M.Yu. Chernyshev, A.M. Zhuravleva, Evolution of psychological approaches to developing education and training in high school: from destruction to integration of integrative sense-didactics, Integration of education 4 (2015) 108.

[6] E.V. Ilyenkov, The school should teach thinking, Public education 1 (1964) 1-16.

[7] A. Yasnitsky, On the history of cultural-historical gestalt psychology: Vygotsky, Luria, Koffka, Levin et al. PsyAnima, Dubna Psychological Journal, Psychological journal of the International University of Nature, Society and Man "Dubna" 1 (2012) 60-97.

[8] A.R. Luria, The development of mental functions in twins, Journal of personality 5(1) (1936) 35-47.

[9] L.S. Vygotsky, A.A. Puzyrei, Letters to students and colleagues, Journal of Russian and East European Psychology 45(2) (2007) 11-60.

[10] C. Junge, P. Valkenburg, M. Dekovich, S. Branje, The building blocks of social competence: Contributions of the Consortium of Individual Development, Developmental cognitive neuroscience 45 (2020) 1-11.

[11] I.A. Yurov, S.L. Rubinstein, Dialectical Materialistic and Humanistic Psychology, Psychologist 4 (2015) 37-84.

[12] V.P. Zinchenko, Consciousness as a subject and matter of psychology, Methodology and History of Psychology 1 (2006) 207-231.

[13] E.G. Simonova, Psychological barriers in professional development of personality, Personality, family and society: issues of pedagogy and psychology 1 (2012) 198-203.

[14] D. Gibson, T. Broadley, J. Downie, P. Wallet, Art in teaching, Evolving Learning 21(2) (2018) 62-73.

[15] L. Bykasova, N. Vovchenko, M. Krewsoun, Modern Transmedia Products Architecture, Media Education, 59(2) (2019) 216-223. 
[16] S.N. Gavrov, N.D. Nikandrov, Education in the process of personality socialization, Actual problems of education 1 (2008) 21-29.

[17] N.A. Barinova, E.V. Karunas, Individual educational program design as a consequence of FSES realization, Kazan Pedagogical journal, 3(110) (2015) 70-75.

[18] M.V. Boguslavskij, E.V. Neborsky, The concept of higher education development in Russia. World of education, 2016. Retrieved from: http://mirnauki.com/PDF/ 07PDMN516.pdf

[19] G. Cappello, D. Felini, R. Hobbs, Reflections on global developments in media literacy education: bridging theory and practice, Journal of Media Literacy Education 3 (2011) 66-73.

[20] S.L. Rubinstein, Problems of general psychology, Moscow, Pedagogy, 1976, 416 p.

[21] D. Gibson, T. Broadley, J. Downie, P. Wallet, Evolving Learning Paradigms: Re-Setting Baselines and Collection Methods of Information and Communication Technology in Education Statistics, Educational Technology \& Society 21(2) (2018) $62-73$.

[22] U.M. Dholakia, R.P. Bagozzi, L.K. Pearo, A social influence model of consumer participation in network-and small-group-based virtual communities, International Journal of Research in Marketing 21(3) (2004) 241-263. 